period transitional metals. In the period commencing with francium and extending to americium, a big drop in the melting point occurred at uranium, while very complicated crystal structures existed for those olements showing allotropy. This was due to the presence of homopolar unsymmetrical binding caused by the filling of the $f$-shells as well as the $d$ and $s$-shells. In uranium, this operation of both $d$ and $f$-states gave rise to an unsymmetrical crystal structure, while on heating the $d$-bonds wero broken, causing anomalies in the linear expansion, abnormally small electrical resistivity and, at higher temperatures, a change in crystal structure to $\beta$ - and $\gamma$-uranium. Americium oxisted in only one form with a peculiar double hexagonal close-packed crystal structure, indicating the boginning of a rare-earth bchaviour with the electrons not forming bonds but existing in independent shells. Thus Dr. Friedel considered that the elements of low atomic number in the range had a structure similar to the transition metals, with a mixture of $d$ - and $f$-orbitals giving rise to diroctional homopolar bonding, while for plutonium and americium the structures were moro analagous to the rare earths, with the electrons in the $f$-shells predominating over those in the $d$-shells.

Some aspects of structure and solid solution were considered by Dr. G. K. Williamson (Atomic Energy Research Establishment, Harwell). The alloying behaviour of uranium was discussed with the view of determining its behaviour empirically. There was negligible solubility in the complex $\alpha$ - and $\beta$-structures and in tho body-centred cubic $\gamma$-structure; it was restricted to the transition elemonts (Group IVA onwards). The Humo-Rothery size factor rule was obeyed for the elements of the first two long periods, but this is not so for elements of the third long poriod, and the reason for this is not yet understood. Uranium forms a large numbor of compounds, but it seems remarkable that, apart from those with a special size factor, no compounds are formed with elements of lower electronegativity. The compounds formed cannot be accounted for on the basis of electron compounds, for the effective valency of uranium is uncortain.

The conference was concluded with a talk by Sir John Cockeroft (Atomic Enorgy Research Establishment, Harwell) on the place of metallurgical development in the atomic programme. Future reactors would require fuel elements operating at higher temperatures, with higher heat ratings and burn-ups than those at present in use. Ratings could be increased in two ways. The surface area to volume ratio of the fuel element could be increased by using clusters of thin rods or plate fuel elements, but those were limited by fabrication problems or by the increaso in the ratio of canning material to fuel. Again, the fuel element temperature could bo increased, but this causes swelling in metallic uranium at $550-600^{\circ} \mathrm{C}$. This difficulty could be overcome by using a 14 per cent molybdenum alloy, but such a degree of alloying is too high for thermal reactors, although it may be applicable for use in fast reactors. At temperatures above $600^{\circ} \mathrm{C}$., it is necessary to use ceramic materials, uranium oxide or uranium carbide, as fuel, but these have their difficulties. With such high operating temperatures, beryllium cans are roquired and experiments have been carried out to test their ability to withstand such temperatures. By a combination of methods, it is hoped to increase the rating to 5-10 MW. per ton compared with 1.3 MW. per ton for the Calder Hall reactor. Sir John mentioned the more advanced reactor typestho Dounreay fast reactor, the high-temperature gas-cooled reactor and the liquid fuel reactor--and concluded with a consideration of other problems, including those of irradiation damage of the steel pressure vessels, and stress corrosion difficulties.

T. E. Arimbone

\title{
THE CHEMISTRY OF TERPENOID COMPOUNDS
}

\begin{abstract}
A SYMPOSIUII on recent advances in the chemistry of terpenoid compounds, organized by the Chemical Socioty, was held in the Chemistry Department, University of Glasgow, during July 11-12. A marked feature of this symposium was the emphasis placed on ideas and methods which had scarcely entered the field even as late as 1950. Terpene chemistry was the first chemistry of natural products in which a wide range of related substances was examined, and the emphasis for many years was on structures. The first great generalization was the 'isoprene rule', which has recently been expanded into the 'biogenetic isoprene rule', and nowadays it is evident from the conference that chemists are not content merely to determine structures but wish to correlate these structures with those of the isoprenoid compounds in general. The term 'biogenesis' was mentioned in some connexion in almost every paper. Another feature was the universal dependence on physical methods for suggesting probable structures : infra-red and ultra-violet spectra and optical rotatory determinations are some of the chiof tools used. Atternpts at total synthesis of terpenoid compounds were described in only two papers.
\end{abstract}

The attendance at the symposium was international, with representatives from several countries including Australia, Canada, France, Groat Britain, Now Zealand, Switzorland and the United States.

The first paper, on the structure of the sesquiterpene ketone zierone (Prof. A. J. Birch, D. J. Collins, R. P. Hildebrand, A. R. Penfold and M. D. Sutherland), is an example of the use of newer methods based largely on absorption spectra. The substance is a derivative of a now natural azulene, and the chief method of structure determination was by dehydrogenation, by methylation at the carbonyl group and adjacent to it, and dehydrogenation, and then a study of the spectra of the resulting azulones. Some probable conclusions can even be reached as to the stereochemistry of the whole molecule by a study of the spectra of dihydrozierone diol produced by osmic acid oxidation. Zierone is chiefly notable in that although it is isoprenoid one of the units is reversed from the normal head-to-tail linkage. In this connexion also Prof. F. Sörm discussed the structure of acorone and laserpitine, both rather remarkable ketonic sesquiterpenes. The latter is an isocadalene derivative with one reversed unit, the former a 
spiro-diketone with a regular linkage, which by migration roactions of known type could be rearranged to an isocadalone derivative. It is suggested that it might in fact represent the typo of linkage between the two series. The use of spectra was again well illustrated in a number of connexions, but notably in the observation that the infra-red spectrum of the fully reduced acorone showed the compound not to belong to any known series of bicyclic sesquiterpones.

A paper by Prof. W. Cocker illustrates another aspect of the effect of light : its ability to isomerize some substances to interesting structures of higher energy-level. In this case the product obtained by irradiation of santonin in aqueous solution and its transformation products were discussed, and it was concluded that the initial product contains a cyclopropane ring. Among other use of spectra, the infra-red adsorption was used for counting the number of methyl groups present. It is an interesting speculation as to how far similar reactions in plants possibly catalysed by othor substances may explain the production of 'improbable' compounds of this nature. Work on irradiation of santonin is proceeding in at least three other laboratories, and the symposium has no doubt facilitated the correlation of these researches. Other irradiation work was later reported by Dr. G. Büchi.

In a not too distantly related field, Dr. F. J. McQuillin considered the autoxidation of sesquiterpenes of the eudesmane series containing an $\alpha \beta$. unsaturated ketone system; similar products were obtained by the use of alkaline persulphate. With carboxyl groups in the correct position lactone rings can be produced in the same position as in santonin.

In this case the autoxidation was much influenced by the configuration of the side-chain.

A number of problems of triterpene structure were presented. Prof. E. R. H. Jones (with T. G. Halsall, W. J. Dunstan and H. Fazakerley) discussed the chemistry of hydroxyhopanone and concluded that it is pentacyclic, but they could not relate the nucleus to a known series. It is thought possibly to bo related to zeorin. All the standard methods, including optical rotatory dispersion, were used in this work. Prof. G. Ourisson (with P. Crabbe, T. Takahashi and M. Palmade) used classical-type methods to elucidate the structure of dipterocarpol. This was converted to a steroid-hormono analogue $(8 \beta: 14 \alpha$-dimethyl-18 nor-nortestosterone) which is biologically completely inactive. It was suggestod that this is due to distortion by axial $8: 18$-methyl groups. The structure of katonic acid ( $3 \alpha$-hydroxyolean-12-en-29-oic acid) was elueidated by Dr. F. E. King (with J. W. W. Morgan) by relating it to the $\beta$-amyrin series. The authors appeared not to know whether to be ploasod with a comparatively easy solution of the problem or disappointed that something more fundamentally novel was not involved.

Prof. H. Erdtman (Stockholm), who was presented with the Flintoff Medal for his achievements in the field of chemical botany, considered very carefully possible uses of chemical constituents in taxonomy. The chief note sounded was of hope, tempered with caution, but obviously a great deal of work must be done before firm conclusions can be reached.

A totally different aspect of the subject was treated by Prof. E. Wenkert (with B. G. Jackson), who discussed the problems encountered in synthetic work in the tricyclic diterpene field. Although the original aim was not completely achieved, Prof.
Wenkert in characteristic fashion turned to advantage apparently incidental observations to provide a reductive (lithium-ammonia) method for the hydrolysis of hindered esters, and in a brilliant exposition extended his biogenotic theories in postulating valid analogies between Friedel-Crafts reactions and biogenotic processes.

Another synthetic problem was discussed by Prof. R. A. Raphael in considering a most ingenious example of the indirect approach in work designed to lead up to the total synthesis of iridodial and related substances.

Natural diterpenes were not neglected. T. G. Halsall (with J. D. Cocker) described the structure and stereochemistry of labdanolic acid and discussed the possible biogenetic significance of the failure of diterpenes and triterpenes to occur together. Dr. W. B. Whalley (with Miss A. Harris, and Prof. A. Robertson) described work leading to the structure of rosono-and rosenono-lactones, the first fungal diterpenes to be structurally elucidated.

The structure of the complex bitter principle limonin, $\mathrm{C}_{28} \mathrm{H}_{30} \mathrm{O}_{8}$, was discussed by Dr. O. Jeger, who was not sure whether it is a triterpene less four carbon atoms or a diterpene plus six carbon atoms. It contains a furan ring, two carbon rings, two lactones and probably two other ether. (epoxide?) rings. Several of its complicated reactions were formulated in a reasonable manner, and a race is now anticipated between organic chemists and X-ray crystallographers for a final solution.

Some extremely energetic threo-dimensional musical chairs was involved in three papers dealing with very complex ring-structures. On the basis of this work there is certainly no need for natural-product chemists to be apologetic about their ability to deal with reaction mechanisms. Prof. A. Büchi confirmed the structure of 'carvone camphor' obtained by illumination of carvone, and showed that it contains a cyclobutane ring the presence of which leads to most interesting rearrangements. Prof. K. Wiesner (alkz. loids from Aconitum napellus) and Prof. R. C. Gookson (with M. E. Trevett) (delpheline) showed that terpene chemists will in future have to take into account the chemistry of nitrogen. The beautiful and complex three-dimensional networks discussed require a threedimensional mind to cope with thom. The reporter was feeling two-dimensional at the time.

The use of infra-red spectra in all the preceding work was appropriately emphasized by Dr. R. N. Jones, who discussed a new method for use with micro-quantities. He also described some potential uses of the method of 'subtracting' spectra.

From the scientific point of view, including selection of subjects, methods of presentation and general smooth running, the symposium was the most successful the author has attended. The high attendance to the last word, and generally expressed opinion, confirm this impression. Discussion was lively and interesting, with particularly notable contributions from the United States. Several very enjoyable social occasions were also provided: a dinner in the beautiful loch and hill country of Aberfoyle, and a Scottish evening with Scots songs and dances and other characteristic Scotch products was attended by kind invitation of Imperial Chemical Industries (Nobel Division). The organizing committee is to be heartily congratulated, and thanks are particularly due to Dr. A. Payne, the local representative of the Chemical Society. A. J. Birch 